\title{
The effect of track alignment irregularity on wheel-rail contact geometry relationship in a turnout zone
}

\author{
$\mathrm{Li} \mathrm{WANG}^{1 *}$, Ping WANG ${ }^{1}$, Shunxi QUAN ${ }^{2}$, Rong $\mathrm{CHEN}^{1}$ \\ 1. MOE Key Laboratory of High-Speed Railway Engineering, Southwest Jiaotong University, Chengdu 610031, China \\ 2. China Railway Siyuan Survey and Design Group Co. Ltd., Wuhan 430063, China
}

\begin{abstract}
The irregularity is a key factor affecting the wheel-rail contact geometry relationship. In this paper, we calculated the wheel-rail contact points at typical sections and obtained the longitudinal variation of the wheel-rail geometry relationship with the trace line method. The profile of the key rail sections was matched by cubic spline curve, and the shape interpolation was realized in non-controlling sections. The results show that the roll angles at each typical section increases gradually with the enlargement of track alignment irregularity. When the flange contact occurs, the roll angle increases dramatically. Proper track alignment irregularity towards the switch rail improves the structure irregularity of the turnout.
\end{abstract}

Key words: track alignment irregularity; wheel-rail geometry relationship; turnout; roll angle

(C) 2012 JMT. All rights reserved.

\section{Introduction}

$\mathrm{T}$ he wheel-rail contact geometry relationship is a basic problem in the rail transit systems. A mismatched wheel-rail surface will lead to serious problems for a running train, such as the instability and high contact stress between the wheel and rail, which may further result in heavy tread wear, fatigue cracks, and high noise [1-3]. Nowadays, the research on the wheel-rail relationship mainly consists of two aspects. One is the wheel-rail contact geometry relationship and the other is the interaction force between the wheel and rail [4-5]. This article is concerned with the former, focusing on the situation when the train runs in a turnout zone. The turnout is a kind of essential railway line equipment used for trains passing from one track to another. Fig. 1 shows the structure of a simple turnout.

The wheel-rail contact geometry relationship in a turnout zone shows a great complexity even for the simplest turnout [6-8].

Ren et al. [9] studied the wheel-rail contact rules at No. 12 turnout and presented a calculation method to evaluate the two-point contact. Cao et al. [10] conducted research on the dynamic responses due to irregularity of

Received Apr. 18, 2012; revision accepted May 30, 2012

*Corresponding author. E-mail: 295289362@qq.com (L.

WANG)

(C) 2012 JMT. All rights reserved

doi: 10.3969/j.issn.2095-087X.2012.03.004

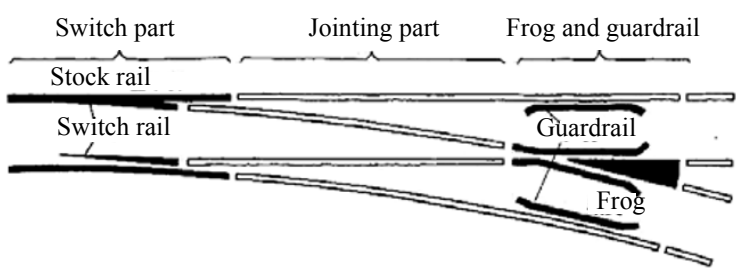

Fig. 1 The structure of simple turnout

No. 38 turnout for high-speed railway and obtained very useful results.

Turnout is a weak link in a railway track system and different types of irregularities occur in the turnout zone. These irregularities could easily influence the trains' running smoothness, comfortableness, and even passengers' safety [11-12]. Thus, it is necessary to analyze the variation of the wheel-rail contact geometry relationship in the presence of the irregularities in turnout zone.

Taking No. 18 turnout for instance, this paper investigates the effect of track alignment irregularity on the wheel-rail contact geometry relationship.

\section{Calculation method}

The study of wheel-rail geometry relationship began with the wheels with simplified cone-tread profile. With the development of research, many shapes of tread were studied. In order to find out the exact wheel-rail contact relationship, the trace line method is desirable [13-17], especially when the shape of the tread is arbitrary. 
This paper investigates the contact geometry relationship between the profiled wheel tread and rail with different cross-sections by the trace line method. The detailed procedures are as follows.

(1) Find some discrete coordinate points in key sections according to the designed profile at each crucial section of No. 18 turnout [18]. The drop height of rail top surface at each crucial section is shown in Table 1 and Table 2.

Fig. 2 shows part of profiles that are produced by the

Table 1 The drop height of switch rail top surface (mm)

\begin{tabular}{ccc}
\hline $\begin{array}{c}\text { Type of } \\
\text { switch rail }\end{array}$ & $\begin{array}{c}\text { Top width } \\
\text { of switch rail }\end{array}$ & Drop height \\
\hline \multirow{3}{*}{ Curved } & 0 & 23 \\
& 5 & 14 \\
& 20 & 4 \\
Straight & 50 & 0 \\
\hline & 0 & 23 \\
& 3 & 14 \\
& 15 & 3 \\
\hline
\end{tabular}

Table 2 The drop height of the nose rail top surface (mm)

\begin{tabular}{ccc}
\hline $\begin{array}{c}\text { Type of } \\
\text { nose rail }\end{array}$ & $\begin{array}{c}\text { Top width } \\
\text { of nose rail }\end{array}$ & Drop height \\
\hline \multirow{3}{*}{ Long } & 0 & 16 \\
& 22.5 & 4 \\
& 40 & 1.4 \\
Short & 50 & 0 \\
\hline \multirow{3}{*}{} & 0 & 23 \\
& 20 & 2 \\
\hline
\end{tabular}

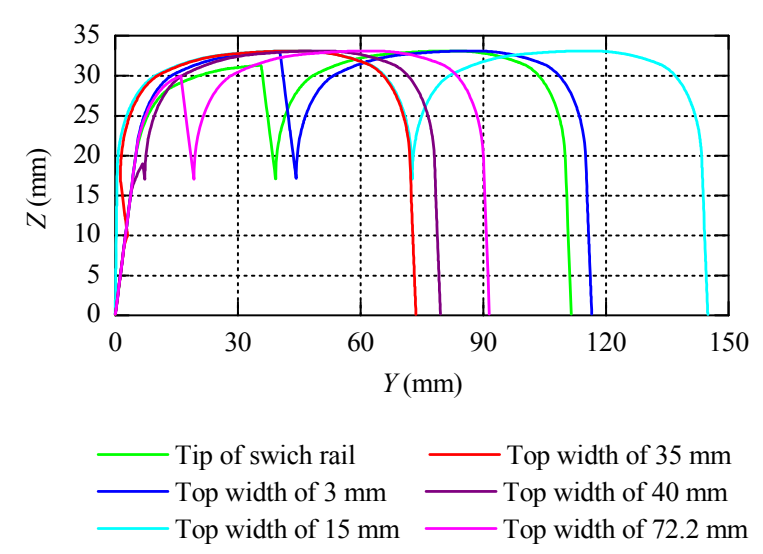

Fig. 2 Part of profiles which produced by the found coordinate points in some key sections selected coordinate points in some key sections, including the tip of switch rail, and the switch rail with top width of 3, 15, 35, 40, and $72.2 \mathrm{~mm}$. $Y$ and $Z$ are the abscissa and vertical coordinates in local coordinate system respectively.

(2) Transform the coordinate points from local coordinate system into global coordinate system. The essence is to give the coordinate points a reasonable move and obtain the new discrete coordinate points. The translation amount could be calculated by

$$
\begin{aligned}
& \Delta Y_{L}=-\frac{S}{2}-Y, \\
& \Delta Y_{R}=\frac{S}{2}-Y,
\end{aligned}
$$

where $\Delta Y_{L}$ is the translation amount for points on the left rail, $\Delta Y_{R}$ is the translation amount for points on the right rail, $S$ is the gauge (1 $435 \mathrm{~mm})$, and $Y$ is the coordinate point's abscissa.

(3) Utilize cubic spline curve to match the profile of the rail with the new discrete coordinate points above and then discretize the profile into coordinate points with equal interval to realize shape interpolation in noncontrolling sections.

(4) Use the coordinate values obtained in the third step and the longitudinal coordinates of each section to form the profiles in non-controlling sections.

(5) Calculate the position of the wheel-rail contact points with the trace line method. Fig. 3 shows the calculation schematic diagram.

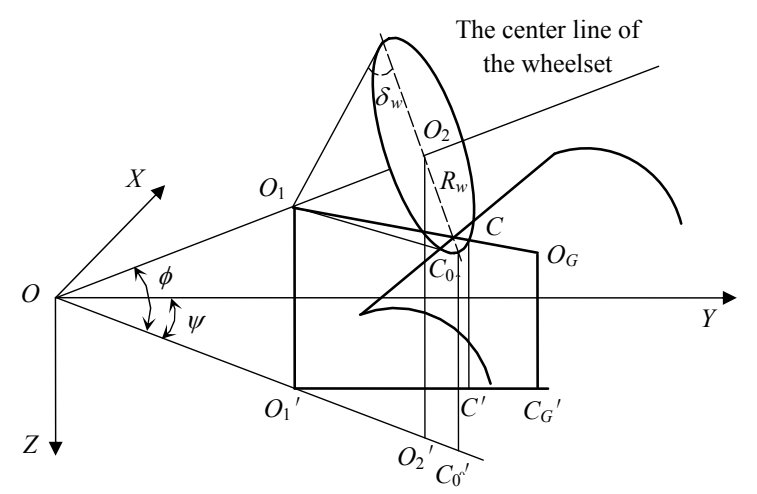

Fig. 3 The calculation schematic diagram of the wheel-rail contact geometry relationship

As presented in Fig. 3, the wheel-rail contact point is at $C$. We could get its coordinate values by three plane equations:

$$
\begin{aligned}
& x=x_{o_{2}}+l_{x} R_{w} \operatorname{tg} \delta_{w}, \\
& y=y_{o_{2}}-R_{w} \frac{l_{x}^{2} l_{y} \operatorname{tg} \delta_{w}+l_{z} m}{1-l_{x}^{2}}+y_{w},
\end{aligned}
$$




$$
z=z_{o_{2}}-R_{w} \frac{l_{x}^{2} l_{z} \operatorname{tg} \delta_{w}-l_{y} m}{1-l_{x}^{2}},
$$

where

$$
m=\sqrt{1-l_{x}^{2}\left(1+\operatorname{tg}^{2} \delta_{w}\right)},
$$

and $l_{x}, l_{y}$ and $l_{z}$ are direction cosines of $x, y$ and $z$ axis respectively:

$$
\begin{aligned}
& l_{x}=-\cos \phi \sin \psi, \\
& l_{y}=\cos \phi \cos \psi, \\
& l_{z}=\sin \phi,
\end{aligned}
$$

In fact, before using the calculation method, we have to make some necessary assumptions. Firstly, the rigidity of the wheel and rail are all strong enough that they could not break in each other. Secondly, the wheel and rail are always in continuous contact with each other and they do not separate from one another. Lastly, the wheel and rail have a common tangent plane.

Then we calculated the positions of the wheel-rail contact points with the trace line method. It is important to stress that the vertical distances of wheel-rail contact points should be zero, and if not, the wheel and rail are not in contact.

\section{Calculation results and analysis}

The effect of track alignment irregularity on wheel-rail geometry relationship is equivalent to the lateral shift of a wheelset [19-21]. Thus, we will give the wheelset a proper lateral shift and assume that the left lateral shift (which means the wheelset deflects right) is positive. In the calculation, the radius of the wheel is $460 \mathrm{~mm}$, the distance between backs of the wheel flanges is $1353 \mathrm{~mm}$, and the yaw angle is out of consideration.

\subsection{Wheel-rail geometry relationship at typical sections}

Fig. 4 shows the variation of wheel-rail contact points on straight stock rail (left steel rail) as the lateral shift increases. The reference point is the point for gauge measurement. Similarly, Fig. 5 describes the variation of wheel-rail contact points on straight switch rail (right steel rail).

From Figs. 4 and 5 we can see that the wheel-rail contact points on straight switch rail at each typical section are all getting close to the wheel flange gradually when the left lateral shift makes the wheelset deflect to right, while the wheel-rail contact points of straight stock rail at each typical section all deviate from the wheel flange gradually. Moreover, when the right shift of the wheelset reaches about $9.0 \mathrm{~mm}$, the wheel-rail contact points at each typical section have all changed dramatically. This trend remains when the right shift happens. Fig. 6 shows the variation of wheel-rail contact points on rail surface as the lateral shift increases.

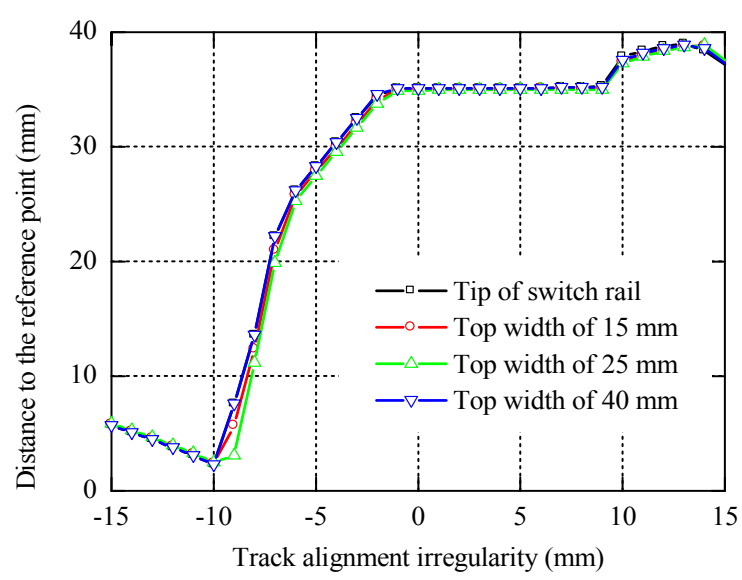

Fig. 4 Variation of wheel-rail contact points on straight stock rail (left steel rail)

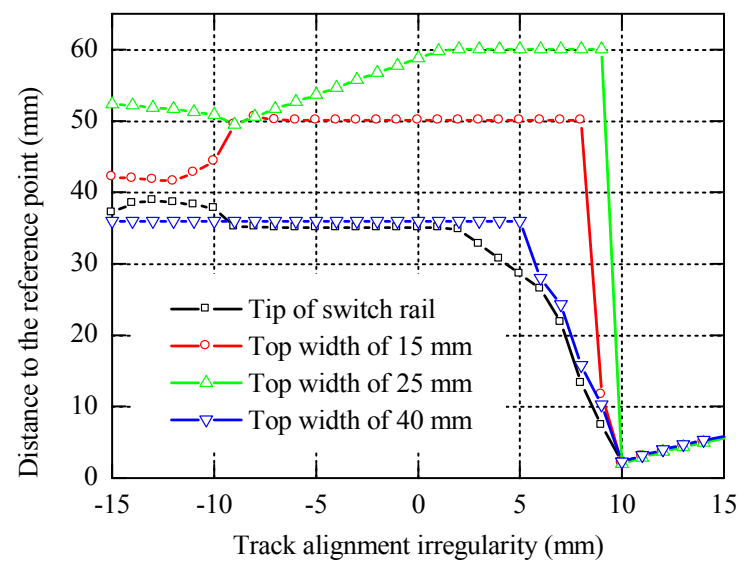

Fig. 5 Variation of wheel-rail contact points on straight switch rail (right steel rail)

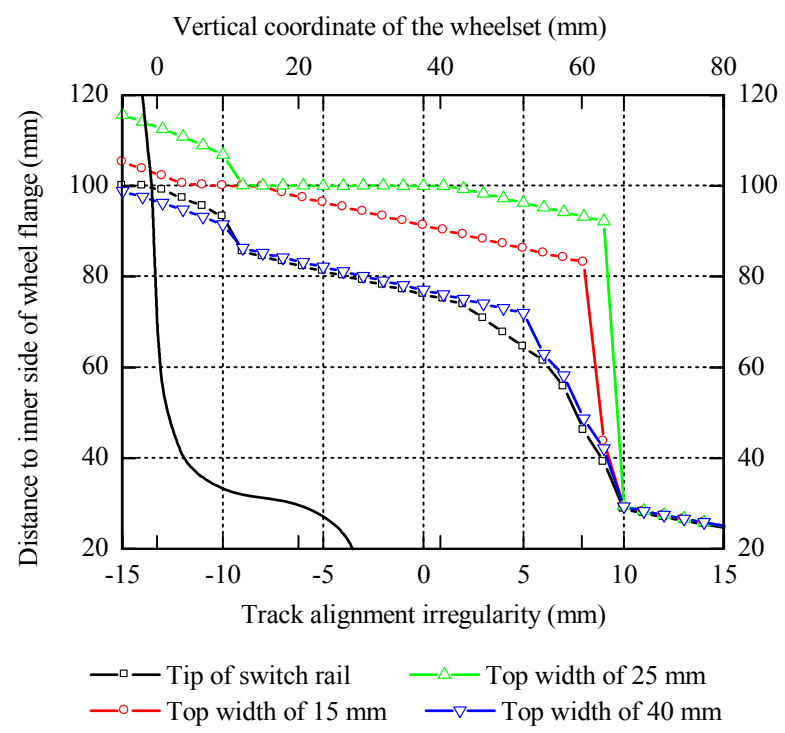

Fig. 6 Variation of wheel-rail contact points on rail surface 
From Figs. 4-6, we find that the right wheel-rail contact points are all located in a large scope of inner side of rail surface and getting close to the wheel flange gradually when the lateral shift ranges from $0 \mathrm{~mm}$ to $9 \mathrm{~mm}$. However, the left wheel-rail contact points appear in a small scope of the lateral side of the rail surface and in the middle of the rail top. This is mainly because the inner side of the wheel flange in the range of $74.3-135 \mathrm{~mm}$ is made up of two straight line segments where slopes are 1:40 and 1:15, respectively. When the wheelset centre deflects to right, the right wheel-rail contact points mainly fall into the range of the rail's arc surface, while the left wheel-rail contact points are all located in the inclined straight line which resembles a cone tread.

Moreover, the effects of track alignment irregularity on each typical section are not the same. Under ideal conditions, the wheel-rail contact points have a tendency of moving toward the outer side of the rail at each typical section [22-23]. Therefore, when the lateral shift ranges from $0 \mathrm{~mm}$ to $9 \mathrm{~mm}$, the wheel-rail contact points at the switch rail are not always in the range of rail's arc surface but located in the inclined straight lines like the situation of the left wheel-rail. This will have unfavorable influences on the wheel-rail wear.

The track alignment irregularity considerably affects the roll angle. As presented in Fig. 7, the roll angles at each typical section increase with the enlargement of track alignment irregularity. When the flange contact happens, the roll angle increases sharply.

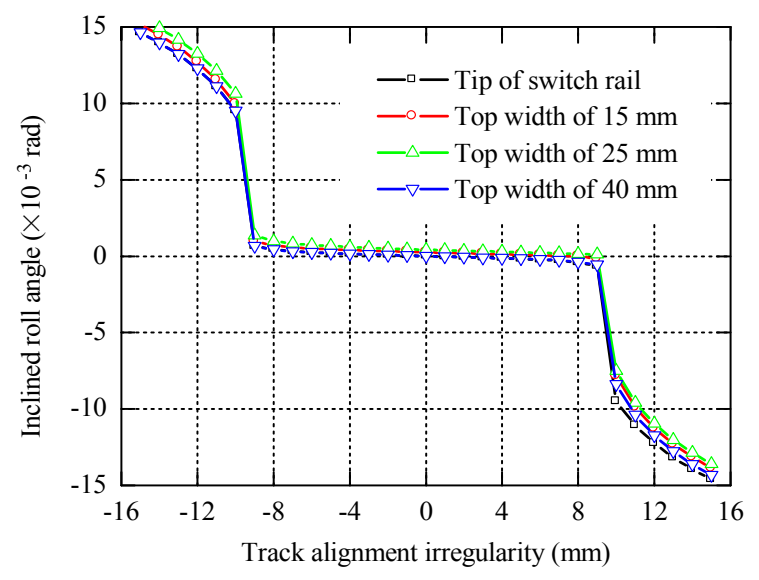

Fig. 7 Variation of roll angle at each typical section

\subsection{Longitudinal variation of the wheel-rail geometry relationship}

The profile of the rail top surface changes with the longitudinal coordinate value at different parts of turnout zone. No matter in the switch zone or frog zone, a $3 \mathrm{D}$ surface graph is produced to describe the wheel-rail contact geometry relationship when taking both track alignment irregularity and longitudinal mileage into consideration. Fig. 8 shows the wheel-rail contact geometry relationship in switch zone when the track alignment irregularity and longitudinal mileage are involved, while Fig. 9 shows the variation in frog zone.

From Figs. 8 and 9, we find that the variation range of wheel-rail contact points does not always increase as the track alignment irregularity increases. When the right lateral shift increases, the variation range becomes smaller; while as the left lateral shift increase, the variation range becomes larger. For example, in the switch zone for the track alignment irregularities of $6 \mathrm{~mm}, 0 \mathrm{~mm}$, and $-6 \mathrm{~mm}$, the corresponding variation ranges of wheelrail contact points are $100.0-72.1 \mathrm{~mm}, 99.7-66.8 \mathrm{~mm}$, and $99.6-60.9 \mathrm{~mm}$, respectively.

This phenomenon may be explained by the following reasons. As the wheelset rolls on the switch part and frog, the wheel-rail contact point first moves right to the outer side of rail surface and then the inner side when the wheel load is transferred. Thus, the wheel-rail contact points' position would have a noticeable variation.

As for the rail surface of $\mathrm{LM}_{\mathrm{A}}$ type, the track align-

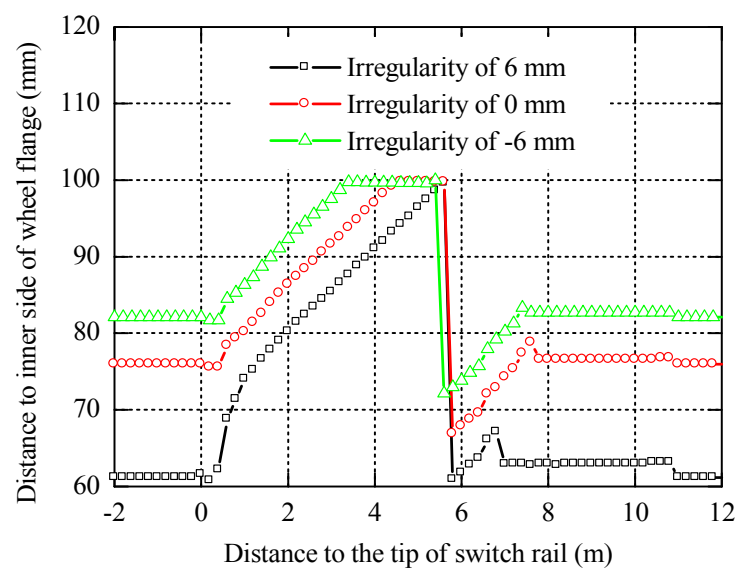

Fig. 8 Longitudinal variation of the wheel-rail contact geometry relationship in switch zone

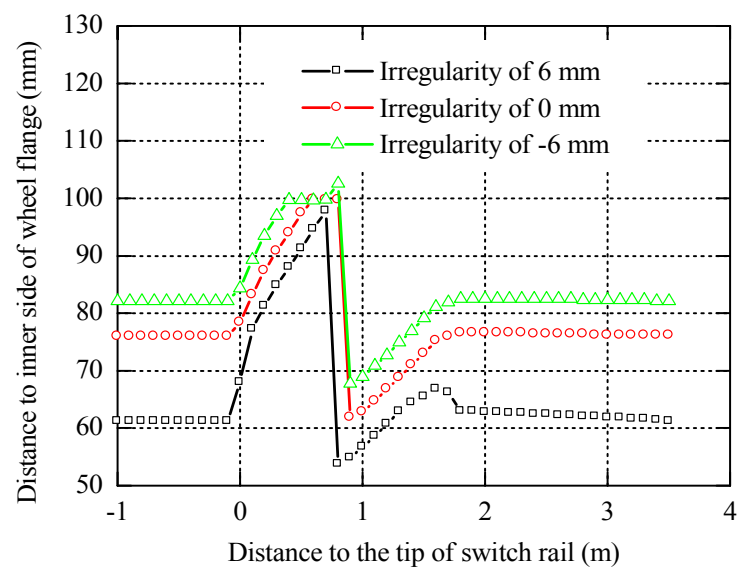

Fig. 9 Longitudinal variation of the wheel-rail contact geometry relationship in frog zone 
ment irregularity does not produce obvious influence on the displacement of wheel-rail contact points when they are close to the outer side of rail surface, while considerable influence when the wheel-rail contact points are close to the inner side of rail surface. That is to say, the track alignment irregularity only influences the contact points greatly when the wheel load is transferred. Thus, from the variation of wheel-rail contact points' position at the side of switch rail (or the nose rail), we can conclude that proper track alignment irregularity towards the switch rail (or the nose rail) is beneficial to improve the structure irregularity of turnout.

\section{Conclusions}

Based on the results and discussions above, the following conclusions can be drawn. (1) When the lateral shift ranges from $0 \mathrm{~mm}$ to $9 \mathrm{~mm}$ due to track alignment irregularity, it will produce unfavorable influence on the wheel-rail wear. (2) The track alignment irregularity also has considerable influences on the roll angle. The roll angles at each typical section increase gradually with the enlargement of track alignment irregularity. When the flange contact happens, the roll angle increases dramatically. (3) Proper track alignment irregularity towards the switch rail (or the nose rail) is beneficial to improving the structure irregularity of turnout.

\section{Acknowledgements}

This research was financially supported by the National Natural Science Foundation (No. 51008256) and the Technological Research and Development Programs of the Ministry of Railways (No. 2010G006-B).

\section{References}

[1] J.M. Yan, Z.Z. Yin, B.L. Guo, et al., Experimental study of the wheel-rail contact geometry relationship, Rolling Stock, 1983, 6(1): 54-57 (in Chinese).

[2] B. Chen, C.G. Wang, S.C. Sun, et al., Effect of wheelrail contact geometric on stability of high-speed passenger car, Railway Locomotive and Car, 2008, 28(1): 189192 (in Chinese).

[3] Q.M. Bu, L.Q. Yao, Study on the geometric relation of wheel-rail contact, Journal of Suzhou University (Natural Science Edition), 2011, 27(3): 79-84 (in Chinese).

[4] L. Li, D.B. Cui, X.S. Jin, State of arts of research on railway wheel profile optimization, Journal of Southwest Jiaotong University, 2009, 41(1): 13-19 (in Chinese).

[5] X.J. Sun, W.X. Zhou, Tread wear and its effect on wheel-rail contact geometric, Rolling Stock, 2010, 48(7): 1-4 (in Chinese).

[6] P. Wang, R. Chen, R.S. Yang, et al., The Design Theory of Jointless Turnout on Bridge, Chengdu: Southwest
Jiaotong University Press, 2011 (in Chinese).

[7] P. Wang, X.Y. Liu, Calculation Theory and Design Method of Jointless Turnout, Chengdu: Southwest Jiaotong University Press, 2007 (in Chinese).

[8] P. Wang, Design Theory and Practice of Turnout in High-Speed Railway, Chengdu: Southwest Jiaotong University Press, 2011 (in Chinese).

[9] Z.S. Ren, S.G. Sun, Study on the wheel-rail contact geometric relation of the turnout zone, Engineering $\mathrm{Me}$ chanics, 2008, 25(11): 223-230 (in Chinese).

[10] Y. Cao, P. Wang, W.H. Zhao, Dynamic responses due to irregularity of No. 38 turnout for high-speed railway, In: Proc. of the third ICTE2011, Chengdu, 2011: 2544-2549.

[11] P. Wang, R. Chen, X.P. Chen, Wheel-rail relationship optimization of switch zone in high-speed railway turnout, In: Proc. of 2009 Int. Conf. on International Conference on Transportation Engineering 2009 (ICTE 2009), Chengdu, 2009: 2833-2838.

[12] P. Wang, R. Chen, X.P. Chen, Optimization of dynamic design for ballastless turnout on bridges in high-speed railways, In: Proc. of 2010 ICCTP 2010, Beijing, 2010: 3305-3312.

[13] K.W. Wang, The track of wheel contact points and the calculation of wheel-rail geometric contact parameters, Journal of Southwest Jiaotong University, 1984, 1(1): 89-99 (in Chinese).

[14] W.H. Zhang, The calculation method of wheel-rail contact points in space, China Railway Science, 2006, 27(4): 76-79 (in Chinese).

[15] Z.S. Ren, Study on wheel-rail multi-point contact calculation, Journal of the China Railway Society, 2011, 33(1): 25-30 (in Chinese).

[16] P.T. Ni, K.W. Wang, W.H. Zhang, et al., Calculation method of wheel-rail contact relationship, Journal of Traffic and Transportation Engineering, 2006, 6(4): 1013 (in Chinese).

[17] P. Xu, C.B. Cai, S.H. Luo, A numerical calculating method for two-point wheel-rail contact, Rolling Stock, 2010, 48(8): 1-5 (in Chinese).

[18] Research Group of High-Speed Turnout, Development report of No. 18 turnout with the speed of $350 \mathrm{~km} / \mathrm{h}$ in ballastless track, Chengdu: MOE Key Laboratory of High-Speed Railway Engineering, 2007 (in Chinese).

[19] S.X. Quan, P. Wang, H.Y. Zhang, The analysis of the influencing factors of rail lateral shift on curve, Railway Engineering, 2010, 2(1): 114-116 (in Chinese).

[20] S.X. Quan, X.K. Wei, P. Wang, Explore and analyse the control methods of lateral and vertical profile irregularities of ballastless track, Railway Standard Design, 2012, 2(1): 11-15 (in Chinese).

[21] Z. Wu, S.X. Quan, X.Y. Liu, Vertical dynamic calculation analysis of elastic bolster in ballastless track, Chinese Railways, 2008, 9(1): 35-39 (in Chinese).

[22] Y. Cao, P. Wang, Design on plane linearity of turnouts as well as researches and applications of drafting system, Railway Standard Design, 2010(11): 23-26 (in Chinese).

[23] Y. Cao, P. Wang, W.H. Zhao, Study on turnout lineshape design based on plane parameters method, Railway Engineering, 2011, 2(1): 101-103 (in Chinese). 